\title{
Modifiable Factors Associated with Cognitive Impairment in 1,143 Japanese Outpatients: The Project in Sado for Total Health (PROST)
}

\author{
Kaori Kitamura ${ }^{a}$ Yumi Watanabe $^{a}$ Kazutoshi Nakamura $^{\text {a }}$ \\ Kazuhiro Sanpei ${ }^{\mathrm{e}}$ Minako Wakasugi ${ }^{b}$ Akio Yokoseki ${ }^{\mathrm{f}}$ Osamu Onodera ${ }^{\mathrm{f}}$ \\ Takeshi Ikeuchig Ryozo Kuwanog ${ }^{9}$ Takeshi Momotsu $^{\mathrm{e}}$ Ichiei Naritac \\ Naoto Endo d \\ ${ }^{a}$ Division of Preventive Medicine, ${ }^{b}$ Center for Inter-Organ Communication Research, \\ 'Division of Clinical Nephrology and Rheumatology, and d Division of Orthopedic Surgery, \\ Department of Regenerative and Transplant Medicine, Niigata University Graduate School \\ of Medical and Dental Sciences, and eJA Niigata Koseiren Sado General Hospital, and \\ Departments of ${ }^{f}$ Molecular Neuroscience and ${ }^{9}$ Molecular Genetics, Brain Research Institute, \\ University of Niigata, Niigata, Japan
}

\section{Key Words}

Aged · Body mass index · Cognition · Cross-sectional study · Dementia - Mini-Mental State

Examination · Epidemiology

\begin{abstract}
Background/Aims: Evidence on modifiable factors associated with cognitive impairment in Japanese patients is scarce. This study aimed to determine modifiable factors for cognitive impairment in a Japanese hospital-based population. Methods: Subjects of this cross-sectional study were 1,143 patients of Sado General Hospital (Niigata, Japan) registered in the Project in Sado for Total Health (PROST) between June 2008 and September 2014. We assessed disease history, body mass index (BMI), leisure time physical activity, walking time, smoking and drinking habits, and consumption of vegetables, fruits, and green tea as predictors, with cognitive impairment defined by the Mini-Mental State Examination (score <24) as an outcome. Multiple logistic regression analysis was performed to calculate odds ratios (ORs) for cognitive impairment. Results: The mean subject age was 68.9 years, and the prevalence of cognitive impairment was $21.5 \%$. Multivariate analysis revealed that age $(p<0.001)$, low BMI $(<21.1$; OR $1.39,95 \%$ CI 1.12-1.72), a history of stroke $(p=0.003)$, a history of myocardial infarction $(p=$ 0.038 ), low fruit consumption ( $p$ for trend $=0.012$ ), and low green tea consumption ( $p$ for trend $=0.032$ ) were independently associated with a higher prevalence of cognitive impair-
\end{abstract}


ment. Conclusions: Modifiable factors, such as low BMI, low fruit consumption, and low green tea consumption, are associated with cognitive impairment. Longitudinal studies will be needed to confirm these findings.

\section{Introduction}

Growing numbers of dementia patients have become an important public health issue worldwide. Currently, approximately 36 million people are affected by dementia globally, and the number is projected to triple by 2050 [1]. An increasing number of dementia patients also represent a major public health burden in Japan, where the elderly population is rapidly growing. The number of dementia patients in Japan was estimated to be 2.8 million in 2010 and is expected to reach 4.7 million in 2025 [2]. Dementia reduces the quality of life of both patients and their families who provide care and causes social and economic loss due to increased medical care costs. As effective treatments for dementia are limited, prevention is a focus of attention.

Modifiable factors associated with cognition and dementia should be determined in view of dementia prevention, and in this context, a number of epidemiological studies have been conducted [3]. A review by Beydoun et al. [3] found lower educational attainment and decreased physical activity to be major predictors, but further studies will be needed to identify other potential modifiable factors in various ethnic groups. Epidemiological studies conducted in Japan have been scarce, with only a few articles mentioned in recent reviews [3, 4], although some studies targeting Japanese populations have recently been published $[5,6]$.

Cognitive impairment appears in the early or intermediate stage of dementia and is thus targeted in the prevention of this disorder. It is also a meaningful outcome in epidemiological studies, given that cognitive impairment in early stages of dementia is not only a high risk factor for dementia but also an important risk factor for frailty [7], which potentially leads to increased care costs [8]. Against this backdrop, this study aimed to determine modifiable factors for cognitive impairment in a Japanese hospital-based population that underwent a cognitive function examination.

\section{Subjects and Methods}

\section{Subjects}

The subjects of the present cross-sectional study were those registered in the patient registry of Sado General Hospital in Sado City, Sado Island, Japan (population of 64,310 as of October 1, 2008; working populations of $24 \%$ for primary, $21 \%$ for secondary, and $54 \%$ for tertiary industries, and per capita income of 2.0 million JPY [9]), during the period between June 2008 and September 2014. Sado Island is located $30 \mathrm{~km}$ off the coast of Niigata City (population of approximately 800,000; working populations of 5\% for primary, 23\% for secondary, and $72 \%$ for tertiary industries, and per capita income of 2.8 million JPY [9]), the capital of Niigata Prefecture, in mainland Japan. This registry, referred to as the Project in Sado for Total Health (PROST), was initiated in June 2008 in conjunction with the Center for Inter-Organ Communication Research, Niigata University Graduate School of Medical and Dental Sciences, and included all outpatients aged 20 years and older. Details regarding PROST have been described elsewhere [10]. Upon registration, cognitive function and blood pressure were examined, and demographic and lifestyle information was collected. For the present study, the inclusion criterion was patients aged 40 years or older, excluding those 
Kitamura et al.: Modifiable Factors Associated with Cognitive Impairment in 1,143 Japanese Outpatients: The Project in Sado for Total Health (PROST)

undergoing kidney dialysis, which is considered an independent predictor of cognitive impairment [11]. As of September 11,2014, a total of 2,161 patients were registered, of whom 1,240 underwent a cognitive function examination. Of these, 97 undergoing dialysis were excluded, and the remaining 1,143 patients were considered the subjects of this study.

\section{Measurements}

Cognitive function was assessed using the Mini-Mental State Examination (MMSE) [12], a brief, validated instrument commonly used to screen for dementia. MMSE scores range from 0 to 30, with lower scores indicating greater cognitive impairment. The area under the receiver operating characteristic curve of MMSE for DSM-III-R-diagnosed dementia in a Japanese population was reported to be as high as 0.980 [13]. Cognitive impairment was defined as an MMSE score of <24 (i.e. MMSE cutoff score of 23/24) $[13,14]$.

Systolic and diastolic blood pressures were measured twice using an automatic sphygmomanometer after an at least 5-min rest. Body weight and height were measured with a digital scale. Height was estimated as twice the value of the arm span [15] for patients whose height was not measured using the scale. Body mass index (BMI) was calculated as weight $(\mathrm{kg})$ divided by height squared $\left(\mathrm{m}^{2}\right)$.

Information on sex, age, disease history, physical activity, smoking and drinking habits, and frequency of vegetable, fruit, and green tea consumption was obtained using a questionnaire. The current history of hypertension and diabetes and the past history of stroke and heart disease were taken. Walking time was indicated as none, 1-29, 30-59, or $\geq 60 \mathrm{~min} /$ day and leisure time physical activity (exercise, brisk walk, etc.) as none, 1-2, 3-4, or $\geq 5$ times/ week. For smoking habit, patients were classified as nonsmoker, past smoker, and current smoker and for alcohol intake as nondrinker, chance drinker, and drinker (at least once a week). The frequency of vegetable, fruit, and green tea consumption was each estimated according to subject responses and classified as none, 1-2, 3-6 times/week, or every day for vegetables and fruits, and none, 1-6 times/week, or every day for green tea.

\section{Statistical Analysis}

Normality was assessed for continuous variables. The Student t test or the Mann-Whitney $\mathrm{U}$ test was used to analyze differences in continuous variables by sex. Simple and multiple logistic regression analyses were performed to calculate odds ratios (ORs) of predictor variables for cognitive impairment (MMSE score <24). Continuous variables were divided into quintiles for OR comparisons, and $\mathrm{p}$ for trend was calculated by logistic regression analysis. SAS statistical package (release 9.4, Cary, N.C., USA) was used for all statistical analyses. A p value $<0.05$ was considered statistically significant.

\section{Statement of Ethics}

Written informed consent was obtained from all subjects. The protocol of PROST was approved by the Ethics Committee of Niigata University School of Medicine.

\section{Results}

The mean subject age was 68.9 years, and the prevalence of cognitive impairment was $21.5 \%$. Subject characteristics by sex are shown in table 1 . There were significant differences in age, height, weight, and BMI, but not in MMSE score, by sex.

Sex- and age-adjusted ORs for cognitive impairment according to levels of predictor variables are shown in table 2. Age was a strong predictor of cognitive impairment. Histories of stroke and myocardial infarction, shorter walking time, less drinking, and lower fruit and 
Table 1. Subject characteristics $(n=1,143)$

\begin{tabular}{|c|c|c|c|c|c|}
\hline \multirow[t]{2}{*}{ Characteristics } & \multicolumn{2}{|l|}{ Men } & \multicolumn{2}{|l|}{ Women } & \multirow[t]{2}{*}{ p value ${ }^{a}$} \\
\hline & mean $\pm \mathrm{SD}$ & $\mathrm{n}$ & mean \pm SD & $\mathrm{n}$ & \\
\hline Age, years & $68.0 \pm 10.7$ & 633 & $70.0 \pm 10.3$ & 510 & 0.002 \\
\hline Body height, cm & $164.3 \pm 7.3$ & 631 & $150.6 \pm 6.6$ & 503 & $<0.001$ \\
\hline Body weight, kg & $66.2 \pm 12.0$ & 631 & $54.5 \pm 11.1$ & 501 & $<0.001$ \\
\hline BMI & $24.4 \pm 3.4$ & 631 & $23.9 \pm 4.4$ & 501 & 0.037 \\
\hline MMSE score & $27^{b}$ & 633 & $27^{b}$ & 510 & $0.314^{\mathrm{c}}$ \\
\hline
\end{tabular}

Data are presented as mean \pm SD except for MMSE score. ${ }^{a}$ The Student $t$ test was used for MMSE score. ${ }^{\mathrm{b}}$ Median. ${ }^{\mathrm{c}}$ Mann-Whitney U test.

green tea consumption were associated with cognitive impairment. Although BMI was not significantly associated with cognitive impairment ( $\mathrm{p}$ for trend $=0.059)$, the lowest quintile group had a significantly higher OR relative to the reference group (3rd quintile).

To determine independent factors associated with cognitive impairment, multiple logistic regression analysis was performed for candidate predictor variables with statistical significance (table 2), including BMI, histories of stroke and myocardial infarction, walking time, drinking habit, fruit consumption, and green tea consumption. Since the association between BMI quintiles and cognitive impairment was U-shaped (table 2), the analysis was performed with BMI as a discrete variable: 1 = BMI 23.2-24.6 (3rd quintile); 2 = BMI 21.1-23.1 (2nd quintile) and BMI 24.7-26.7 (4th quintile), and $3=\mathrm{BMI}<21.1$ (1st quintile) and BMI $\geq 26.8$ (5th quintile). Age, BMI (discrete), histories of stroke and myocardial infarction, and consumption of fruit and green tea were found to be independent predictors of cognitive impairment (table 3). The prevalence of cognitive impairment was much higher in the $\geq 80$-year-old age group $(45.7 \%)$ than in the other groups, and thus, we conducted a subgroup analysis in the $<80$ - and $\geq 80$-year-old age groups ( $\mathrm{n}=970$ and $\mathrm{n}=173$, respectively). Age (OR 1.08, 95\% CI 0.96-1.21, $\mathrm{p}<0.001$ ), history of stroke (OR 1.93, 95\% CI 1.19-3.13, p = 0.007), and fruit consumption (OR $0.86,95 \%$ CI $0.68-0.97, \mathrm{p}=0.022$ ) were significant predictors in the $<80$-year-old age group.

\section{Discussion}

The present study showed that age, BMI, self-reported history of cerebrovascular and cardiovascular diseases, and consumption of fruits and green tea were independently associated with the prevalence of cognitive impairment as assessed by the MMSE.

In this study, a low BMI was significantly associated with a high prevalence of cognitive impairment. The association between BMI and cognitive impairment has been somewhat contradictory in the literature. A systematic review by Gorospe and Dave [16] found a high BMI to be a risk factor for dementia. Being overweight, a characteristic feature of metabolic syndrome, is associated with insulin resistance and hypertension, both of which are risk factors for cognitive impairment and dementia [17]. Recent reports suggest that the relationship between BMI and cognition is dependent on age (e.g. midlife vs. late life) $[18,19]$. Most epidemiological studies [19] have found obesity in midlife to be a risk factor for the development of dementia, whereas a high BMI in late life is a protective factor [19]. According to our data stratified by age groups (table 4), the lowest-BMI group in the older-age group ( $\geq 70$ years of age) is at high risk of developing cognitive impairment (adjusted OR 2.19), which is in line with the results of previous studies targeting older individuals [19]. 
Kitamura et al.: Modifiable Factors Associated with Cognitive Impairment in 1,143 Japanese Outpatients: The Project in Sado for Total Health (PROST)

Table 2. ORs for cognitive impairment (MMSE score <24) according to levels of predictor variables $(n=1,143)$

\begin{tabular}{|c|c|c|c|c|}
\hline Predictor variables & Subjects, n & $\begin{array}{l}\text { Cognitive } \\
\text { impairment, n } \\
\text { (prevalence, \%) }\end{array}$ & $\begin{array}{l}\text { Unadjusted } \\
\text { OR (95\% CI) }\end{array}$ & $\begin{array}{l}\text { Adjusted }^{\mathrm{a}} \\
\text { OR (95\% CI) }\end{array}$ \\
\hline \multicolumn{3}{|l|}{ Sex } & $\mathrm{p}=0.858$ & $\mathrm{p}=0.359$ \\
\hline Women & 510 & $111(21.8)$ & 1 (ref.) & 1 (ref.) \\
\hline Men & 633 & $135(21.3)$ & $0.97(0.73-1.29)$ & $1.15(0.85-1.56)$ \\
\hline \multicolumn{3}{|l|}{ Age } & $\mathrm{p}$ for trend $<0.001$ & $\mathrm{p}$ for trend $<0.001$ \\
\hline$<60$ years & 210 & $10(4.8)$ & 1 (ref.) & 1 (ref.) \\
\hline 60-69 years & 319 & $39(12.2)$ & $2.79(1.36-5.71)$ & $2.83(1.38-5.82)$ \\
\hline $70-79$ years & 441 & $118(26.8)$ & $7.31(3.74-14.27)$ & $7.31(3.74-14.27)$ \\
\hline$\geq 80$ years & 173 & $79(45.7)$ & $16.81(8.33-33.91)$ & $16.63(8.22-33.61)$ \\
\hline \multicolumn{3}{|l|}{$\mathrm{BMI}$} & $\mathrm{p}$ for trend $=0.734$ & $\mathrm{p}$ for trend $=0.059$ \\
\hline 1st quintile $(<21.1)$ & 227 & $68(30.0)$ & $1.71(1.11-2.64)$ & $1.75(1.09-2.81)$ \\
\hline 2nd quintile (21.1-23.1) & 226 & $45(19.9)$ & $1.06(0.67-1.70)$ & $1.16(0.72-1.89)$ \\
\hline 3rd quintile $(23.2-24.6)$ & 227 & $43(18.9)$ & 1 (ref.) & 1 (ref.) \\
\hline 4 th quintile $(24.7-26.7)$ & 227 & $43(18.9)$ & $1.00(0.63-1.60)$ & $1.25(0.76-2.06)$ \\
\hline 5 th quintile $(\geq 26.8)$ & $\begin{array}{l}225 \\
11 \text { missing values }\end{array}$ & $47(20.9)$ & $1.13(0.71-1.79)$ & $1.50(0.92-2.45)$ \\
\hline \multicolumn{3}{|l|}{ Self-reported history of hypertension } & $\mathrm{p}$ for trend $=0.686$ & $\mathrm{p}$ for trend $=0.065$ \\
\hline No & 433 & $96(22.2)$ & 1 (ref.) & 1 (ref.) \\
\hline Yes & $\begin{array}{l}709 \\
1 \text { missing value }\end{array}$ & $150(21.2)$ & $0.94(0.71-1.26)$ & $0.75(0.55-1.02)$ \\
\hline \multicolumn{3}{|l|}{ Self-reported history of diabetes } & $\mathrm{p}$ for trend $=0.078$ & $\mathrm{p}$ for trend $=0.771$ \\
\hline No & 816 & $187(22.9)$ & 1 (ref.) & 1 (ref.) \\
\hline Yes & $\begin{array}{l}325 \\
2 \text { missing values }\end{array}$ & $59(18.2)$ & $0.75(0.54-1.03)$ & $0.95(0.67-1.35)$ \\
\hline \multicolumn{3}{|l|}{ Self-reported history of stroke } & $\mathrm{p}<0.001$ & $\mathrm{p}=0.005$ \\
\hline No & 992 & 195 (19.7) & 1 (ref.) & 1 (ref.) \\
\hline Yes & $\begin{array}{l}149 \\
2 \text { missing values }\end{array}$ & $51(34.2)$ & $2.13(1.47-3.09)$ & $1.80(1.20-2.71)$ \\
\hline \multicolumn{3}{|c|}{ Self-reported history of myocardial infarction } & $p=0.002$ & $\mathrm{p}=0.032$ \\
\hline No & 1,089 & 225 (20.7) & 1 (ref.) & 1 (ref.) \\
\hline Yes & $\begin{array}{l}53 \\
1 \text { missing value }\end{array}$ & $21(39.6)$ & $2.52(1.43-4.45)$ & $1.97(1.06-3.66)$ \\
\hline \multicolumn{3}{|l|}{ Systolic blood pressure } & $\mathrm{p}$ for trend $=0.840$ & $\mathrm{p}$ for trend $=0.362$ \\
\hline 1st quintile $(<117 \mathrm{~mm} \mathrm{Hg})$ & 207 & $50(24.2)$ & 1 (ref.) & 1 (ref.) \\
\hline 2nd quintile $(117-127 \mathrm{~mm} \mathrm{Hg})$ & 236 & $52(22.0)$ & $0.93(0.60-1.44)$ & $0.96(0.59-1.54)$ \\
\hline 3rd quintile (128-139 mm Hg) & 235 & $42(17.9)$ & $0.72(0.45-1.13)$ & $0.70(0.43-1.15)$ \\
\hline 4th quintile $(140-150 \mathrm{~mm} \mathrm{Hg})$ & 223 & $50(22.4)$ & $0.95(0.61-1.48)$ & $0.92(0.57-1.48)$ \\
\hline 5 th quintile $(\geq 151 \mathrm{~mm} \mathrm{Hg})$ & $\begin{array}{l}230 \\
12 \text { missing values }\end{array}$ & $51(22.2)$ & $0.94(0.60-1.46)$ & $0.79(0.49-1.27)$ \\
\hline \multicolumn{3}{|l|}{ Diastolic blood pressure } & $\mathrm{p}$ for trend $=0.011$ & $\mathrm{p}$ for trend $=0.755$ \\
\hline 1st quintile $(<63 \mathrm{~mm} \mathrm{Hg})$ & 205 & $59(28.8)$ & 1 (ref.) & 1 (ref.) \\
\hline 2nd quintile (63-69 $\mathrm{mm} \mathrm{Hg}$ ) & 236 & $50(21.2)$ & $0.70(0.46-1.08)$ & $0.89(0.55-1.42)$ \\
\hline 3rd quintile (70-76 $\mathrm{mm} \mathrm{Hg}$ ) & 234 & $54(23.1)$ & $0.79(0.51-1.20)$ & $1.11(0.70-1.77)$ \\
\hline 4 th quintile $(77-84 \mathrm{~mm} \mathrm{Hg})$ & 224 & $40(17.9)$ & $0.57(0.36-0.90)$ & $0.84(0.51-1.39)$ \\
\hline 5th quintile ( $\geq 85 \mathrm{~mm} \mathrm{Hg}$ ) & $\begin{array}{l}232 \\
12 \text { missing values }\end{array}$ & $42(18.1)$ & $0.58(0.37-0.91)$ & $1.03(0.61-1.74)$ \\
\hline \multicolumn{3}{|l|}{ Leisure-time physical activity } & $\mathrm{p}$ for trend $=0.478$ & $\mathrm{p}$ for trend $=0.500$ \\
\hline None & 680 & $156(22.9)$ & $1.03(0.71-1.49)$ & $1.04(0.70-1.53)$ \\
\hline 1-2 times/week & 123 & $20(16.3)$ & $0.67(0.38-1.20)$ & $0.72(0.39-1.33)$ \\
\hline 3-4 times/week & 73 & $10(13.7)$ & $0.55(0.26-1.15)$ & $0.54(0.25-1.18)$ \\
\hline$\geq 5$ times/week & $\begin{array}{l}214 \\
53 \text { missing values }\end{array}$ & $48(22.4)$ & 1 (ref.) & 1 (ref.) \\
\hline
\end{tabular}


Table 2 (continued)

\begin{tabular}{|c|c|c|c|c|}
\hline Predictor variables & Subjects, $\mathrm{n}$ & $\begin{array}{l}\text { Cognitive } \\
\text { impairment, } \mathrm{n} \\
\text { (prevalence, \%) }\end{array}$ & $\begin{array}{l}\text { Unadjusted } \\
\text { OR (95\% CI) }\end{array}$ & $\begin{array}{l}\text { Adjusted }^{\mathrm{a}} \\
\text { OR }(95 \% \mathrm{CI})\end{array}$ \\
\hline Walking time & & & $\mathrm{p}$ for trend $=0.009$ & $\mathrm{p}$ for trend $=0.052$ \\
\hline $0 \mathrm{~min} /$ week & 37 & $15(40.5)$ & $2.75(1.39-5.42)$ & $2.41(1.13-5.14)$ \\
\hline $1-29 \mathrm{~min} /$ week & 149 & $36(24.2)$ & $1.28(0.85-1.94)$ & $1.23(0.79-1.92)$ \\
\hline $30-59 \mathrm{~min} /$ week & 135 & $30(22.2)$ & $1.15(0.74-1.79)$ & $1.06(0.66-1.69)$ \\
\hline$\geq 60 \mathrm{~min} /$ week & $\begin{array}{c}769 \\
53 \text { missing values }\end{array}$ & 153 (19.9) & 1 (ref.) & 1 (ref.) \\
\hline Smoking & & & $\mathrm{p}=0.247$ & $\mathrm{p}=0.098$ \\
\hline Nonsmoker & 616 & 135 (21.9) & 1 (ref.) & 1 (ref.) \\
\hline Past smoker & 377 & $88(23.3)$ & $1.09(0.80-1.47)$ & $1.40(0.90-2.17)$ \\
\hline Current smoker & $\begin{array}{c}149 \\
1 \text { missing value }\end{array}$ & $23(15.4)$ & $0.65(0.40-1.06)$ & $1.68(0.91-3.09)$ \\
\hline Alcohol intake & & & $\mathrm{p}<0.001$ & $\mathrm{p}=0.024$ \\
\hline Nondrinker & 471 & $129(27.4)$ & 1 (ref.) & 1 (ref.) \\
\hline Chance drinker & 304 & $61(20.1)$ & $0.67(0.47-0.94)$ & $0.73(0.50-1.09)$ \\
\hline Drinker at least once/week & $\begin{array}{l}367 \\
1 \text { missing value }\end{array}$ & $56(15.3)$ & $0.48(0.34-0.68)$ & $0.66(0.42-1.02)$ \\
\hline Vegetable consumption & & & $\mathrm{p}$ for trend $=0.100$ & $\mathrm{p}$ for trend $=0.616$ \\
\hline None & 18 & $2(11.1)$ & $0.44(0.10-1.91)$ & $0.76(0.16-3.66)$ \\
\hline 1-2 times/week & 39 & $7(18.0)$ & $0.76(0.33-1.75)$ & $1.54(0.62-3.83)$ \\
\hline $3-6$ times/week & 52 & $7(13.5)$ & $0.54(0.24-1.22)$ & $1.26(0.52-30.5)$ \\
\hline Every day & $\begin{array}{l}1,033 \\
1 \text { missing value }\end{array}$ & $230(22.3)$ & 1 (ref.) & 1 (ref.) \\
\hline Fruit consumption & & & $\mathrm{p}$ for trend $=0.757$ & $\mathrm{p}$ for trend $=0.001$ \\
\hline None & 120 & $29(24.2)$ & $1.10(0.70-1.75)$ & $2.24(1.31-3.81)$ \\
\hline 1-2 times/week & 207 & $48(23.2)$ & $1.04(0.72-1.52)$ & $1.59(1.04-2.43)$ \\
\hline $3-6$ times/week & 231 & $38(16.5)$ & $0.68(0.46-1.01)$ & $0.86(0.56-1.32)$ \\
\hline Every day & $\begin{array}{c}584 \\
1 \text { missing value }\end{array}$ & $131(22.4)$ & 1 (ref.) & 1 (ref.) \\
\hline Green tea consumption & & & $\mathrm{p}$ for trend $=0.034$ & $\mathrm{p}$ for trend $=0.007$ \\
\hline None & 539 & $133(24.7)$ & 1 (ref.) & 1 (ref.) \\
\hline 1-6 times/week & 134 & $21(15.7)$ & $0.57(0.34-0.94)$ & $0.72(0.42-1.24)$ \\
\hline Every day & $\begin{array}{l}467 \\
3 \text { missing values }\end{array}$ & $90(19.3)$ & $0.73(0.54-0.99)$ & $0.65(0.47-0.89)$ \\
\hline
\end{tabular}

${ }^{\text {a }}$ Adjusted for age and sex (except for the variables sex and age); sex was adjusted for age, and age was adjusted for sex.

According to a meta-analysis by Anstey et al. [18], a U-shaped relationship was found between midlife BMI and later risk of dementia, i.e. both underweight and overweight individuals are at risk. Moreover, a recent large cohort study showed that underweight individuals are at an increased risk of dementia in all age groups [20]. Our findings are consistent with these reports in that the observed association was nearly U-shaped, although risk in the 5th quintile of BMI was marginal. Taken together, a low BMI appears to be a risk factor for cognitive impairment.

It remains unclear why a lower BMI is associated with a higher prevalence of cognitive impairment, but this could be related to low levels of dementia-related molecules, such as leptin and adiponectin, which are protective of cognitive function [19]. Moreover, a lower $\mathrm{BMI}$ is associated with in vivo biomarkers of cerebral amyloid and tau, suggesting that neuropathologic changes may occur in areas including the hypothalamus that play regulatory roles in energy metabolism and food intake [21]. It should be noted, however, that there may be a 
Table 3. Results of multiple logistic regression analysis with cognitive impairment (MMSE score <24) as an outcome $(n=1,143)$

\begin{tabular}{|c|c|c|}
\hline Predictor variables ${ }^{\mathrm{a}}$ & $\begin{array}{l}\text { Adjusted OR } \\
(95 \% \mathrm{CI})\end{array}$ & $\mathrm{p}$ value \\
\hline Age (years) & $1.11(1.08-1.13)$ & $<0.001$ \\
\hline Body mass index & $1.39(1.12-1.72)$ & 0.003 \\
\hline History of stroke ( $0=$ absent; $1=$ present $)$ & $1.88(1.24-2.85)$ & 0.003 \\
\hline History of myocardial infarction ( $0=$ absent; 1 = present $)$ & $1.95(1.04-3.66)$ & 0.038 \\
\hline Walking time $(0=$ none; $1=1-29 ; 2=30-59 ; 4=\geq 60 \mathrm{~min} / \mathrm{week})$ & $0.87(0.73-1.04)$ & 0.132 \\
\hline Alcohol intake $(0=$ nondrinker; $1=$ chance drinker; $3=$ drinker $)$ & $0.86(0.70-1.04)$ & 0.119 \\
\hline Fruit consumption ( $0=$ none; $1=1-2 ; 2=3-6 ; 3=7$ times $/$ week $)$ & $0.82(0.70-0.96)$ & 0.012 \\
\hline Green tea consumption $(0=$ none; $1=1-6 ; 2=7$ times $/$ week $)$ & $0.83(0.70-0.98)$ & 0.032 \\
\hline
\end{tabular}

${ }^{a}$ All variables are included in the multivariate model. ${ }^{\mathrm{b}} \mathrm{BMI}$ is categorized as $1=23.2-24.6$ (3rd quintile); $2=21.1-23.1$ ( 2 nd quintile) and 24.7-26.7 ( 4 th quintile), and $3=<21.1$ ( 1 st quintile) and $\geq 26.8$ (5th quintile) given the U-shaped association between BMI and cognitive impairment as shown in table 2 .

Table 4. ORs for cognitive impairment (MMSE score <24) according to levels of BMI stratified by age groups

\begin{tabular}{|c|c|c|c|c|}
\hline Predictor variables & Subjects, $\mathrm{n}$ & $\begin{array}{l}\text { Cognitive } \\
\text { impairment, } \\
\text { n (prevalence, \%) }\end{array}$ & $\begin{array}{l}\text { Unadjusted OR (95\% } \\
\mathrm{CI})\end{array}$ & $\begin{array}{l}\text { Adjusted }{ }^{\mathrm{a}} \text { OR (95\% } \\
\text { CI) }\end{array}$ \\
\hline \multicolumn{5}{|c|}{ BMI; $\leq 69$ years of age $(n=523)$} \\
\hline$<21.1$ & 90 & $8(8.9)$ & $0.71(0.27-1.89)$ & $0.76(0.30-2.09)$ \\
\hline $21.1-23.1$ & 105 & $9(8.6)$ & $0.73(0.28-1.89)$ & $0.70(0.27-1.83)$ \\
\hline $23.2-24.6$ & 88 & $10(11.4)$ & 1 (ref.) & 1 (ref.) \\
\hline $24.7-26.7$ & 114 & $8(7.0)$ & $0.59(0.22-1.56)$ & $0.61(0.23-1.64)$ \\
\hline$\geq 26.8$ & 126 & $14(11.1)$ & $0.98(0.41-2.31)$ & $1.06(0.44-2.55)$ \\
\hline \multicolumn{5}{|c|}{ BMI; $\geq 70$ years of age $(n=609)$} \\
\hline$<21.1$ & 137 & $60(43.8)$ & $2.35(1.41-3.93)$ & $2.19(1.27-3.78)$ \\
\hline $21.1-23.1$ & 121 & $36(29.8)$ & $1.36(0.78-2.36)$ & $1.36(0.77-2.41)$ \\
\hline $23.2-24.6$ & 139 & $33(23.7)$ & 1 (ref.) & 1 (ref.) \\
\hline $24.7-26.7$ & 113 & $35(31.0)$ & $1.44(0.83-2.52)$ & $1.61(0.90-2.88)$ \\
\hline$\geq 26.8$ & 99 & $33(33.3)$ & $1.62(0.91-2.85)$ & $1.67(0.93-3.02)$ \\
\hline
\end{tabular}

${ }^{a}$ Adjusted for age and sex.

reverse causal relationship, i.e. changes in eating habits of patients with cognitive impairment (e.g. appetite loss) might have led to a low BMI.

In the present study, lower fruit consumption was associated with a higher prevalence of cognitive impairment. Although limited epidemiological evidence exists regarding fruit consumption $[22,23]$, associations between greater fruit and vegetable intake and better cognitive performance have been suggested $[24,25]$. High levels of antioxidants and/or macronutrients from fruits and vegetables reportedly have favorable effects on cognitive function [22]. However, the present study did not detect an association between vegetable consumption and the prevalence of cognitive impairment. This may be due to subjects' responses to the question of vegetable consumption being clustered in the 'every day' group.

Green tea consumption was also a protective factor against cognitive impairment. Consistent with this, previous cross-sectional [26] and longitudinal [6] studies also reported 
Kitamura et al.: Modifiable Factors Associated with Cognitive Impairment in 1,143 Japanese Outpatients: The Project in Sado for Total Health (PROST)

that consumption of green tea, but not black tea or coffee, protects against cognitive impairment, suggesting that the effects of green tea consumption may be independent of caffeine intake, which is a possible factor for improved cognitive function [3]. Since green tea is widely consumed in Japan, further studies to accumulate evidence are warranted.

In agreement with our study, recent review articles showed with sufficient evidence that cognitively stimulating activities, including physical and social activities, are modifiable protective factors $[3,27]$, and that moderate alcohol consumption may also be protective against cognitive impairment [27]. However, conflicting results have been reported on the putative protective role of healthy dietary habits and other lifestyle factors [3, 27]. Further well-designed longitudinal studies are needed, especially in Asian populations.

As described in the Subjects section, Sado is considered rural in comparison to urban cities such as Niigata City in Japan. The rural aspect of the study location is also characterized by the fact that Sado Island is within uneasy access of mainland Japan. Although the way of living is not different from that on the mainland, findings of the present study may not be generalizable to urban populations.

This study has several limitations. First, our subjects were outpatients of a general hospital and may not represent the general population of the same age group. In addition, outpatients have various health problems, which may have confounded predictor-outcome associations in this study. Second, we did not assess subject education level, an important factor associated with cognitive impairment [3]. This may also have confounded the observed associations. Third, self-reported variables are prone to misclassification bias due, in part, to errors of recall. Finally, our study used a cross-sectional design that does not necessarily imply causal relationships and did not assess all modifiable factors associated with cognitive impairment. Further studies will be needed to confirm our results.

In conclusion, the present study demonstrated that some modifiable factors, such as low BMI, low fruit consumption, and low green tea consumption, as well as a history of vascular disease, are associated with a high prevalence of cognitive impairment in a Japanese population. Longitudinal studies should be performed to confirm these findings.

\section{Acknowledgements}

This study was supported in part by a grant-in-aid for PROST from the Ministry of Education, Culture, Sports, Science and Technology of Japan, and by a JSPS KAKENHI grant (No. 26860436, 15H04782). We used the supercomputer of ACCMS, Kyoto University.

\section{Disclosure Statement}

The authors report no conflicts of interest.

\section{References}

1 World Health Organization and Alzheimer's Disease International: Dementia: A Public Health Priority. Geneva, World Health Organization, 2013.

2 Health and Welfare Statistics Association: Kokumin-no-Fukushi-to-Kaigo-no-Doko (Trend of Welfare and Care in Japan) 2015/2016 (in Japanese). Tokyo, Health and Welfare Statistics Association, 2015.

-3 Beydoun MA, Beydoun HA, Gamaldo AA, Teel A, Zonderman AB, Wang Y: Epidemiologic studies of modifiable factors associated with cognition and dementia: systematic review and meta-analysis. BMC Public Health $2014 ; 14: 643$. 
Kitamura et al.: Modifiable Factors Associated with Cognitive Impairment in 1,143 Japanese Outpatients: The Project in Sado for Total Health (PROST)

-4 Deckers K, van Boxtel MP, Schiepers OJ, de Vugt M, Muñoz Sánchez JL, Anstey KJ, Brayne C, Dartigues JF, Engedal K, Kivipelto M, Ritchie K, Starr JM, Yaffe K, Irving K, Verhey FR, Köhler S: Target risk factors for dementia prevention: a systematic review and Delphi consensus study on the evidence from observational studies. Int J Geriatr Psychiatry 2015;30:234-246.

5 Ozawa M, Ninomiya T, Ohara T, Doi Y, Uchida K, Shirota T, Yonemoto K, Kitazono T, Kiyohara Y: Dietary patterns and risk of dementia in an elderly Japanese population: the Hisayama Study. Am J Clin Nutr 2013;97: 1076-1082.

6 Noguchi-Shinohara M, Yuki S, Dohmoto C, Ikeda Y, Samuraki M, Iwasa K, Yokogawa M, Asai K, Komai K, Nakamura H, Yamada M: Consumption of green tea, but not black tea or coffee, is associated with reduced risk of cognitive decline. PLoS One 2014;9:e96013.

7 Robertson DA, Savva GM, Coen RF, Kenny RA: Cognitive function in the prefrailty and frailty syndrome. J Am Geriatr Soc 2014;62:2118-2124.

-8 Campbell JC, Ikegami N: Long-term care insurance comes to Japan. Health Aff 2000;19:26-39.

9 Niigata Prefectural Government: Niigata Prefecture Statistics Box (in Japanese). http://www.pref.niigata. lg.jp/tokei/.

10 Watanabe Y, Kitamura K, Nakamura K, Sanpei K, Wakasugi M, Yokoseki A, Onodera O, Ikeuchi T, Kuwano R, Momotsu T, Narita I, Endo N: Elevated C-reactive protein is associated with cognitive decline in outpatients of a general hospital: the Project in Sado for Total Health (PROST). Dement Geriatr Cogn Disord Extra 2016;6: 10-19.

11 Griva K, Stygall J, Hankins M, Davenport A, Harrison M, Newman SP: Cognitive impairment and 7-year mortality in dialysis patients. Am J Kidney Dis 2010;56:693-703.

$\$ 12$ Folstein MF, Folstein SE, McHugh PR: 'Mini-mental state'. A practical method for grading the cognitive state of patients for the clinician. J Psychiatr Res 1975;12:189-198.

13 Maki N, Ikeda M, Hokoishi K, Nebu A, Komori K, Hirono N, Tanabe H: The validity of the MMSE and SMQ as screening tests for dementia in the elderly general population: a study of one rural community in Japan. Dement Geriatr Cogn Disord 2000;11:193-196.

$>14$ Lin JS, O'Connor E, Rossom RC, Perdue LA, Burda BU, Thompson M, Eckstrom E: Screening for Cognitive Impairment in Older Adults: An Evidence Update for the US Preventive Services Task Force [Internet]. Rockville, Agency for Healthcare Research and Quality, 2013, Evidence Syntheses, No 107, pp 25-29.

15 Kwok T, Whitelaw MN: The use of armspan in nutritional assessment of the elderly. J Am Geriatr Soc 1991;39: 492-496.

16 Gorospe EC, Dave JK: The risk of dementia with increased body mass index. Age Ageing 2007;36:23-29.

-17 Panza F, Frisardi V, Capurso C, Imbimbo BP, Vendemiale G, Santamato A, D’Onofrio G, Seripa D, Sancarlo D, Pilotto A, Solfrizzi V: Metabolic syndrome and cognitive impairment: current epidemiology and possible underlying mechanisms. J Alzheimers Dis 2010;21:691-724.

18 Anstey KJ, Cherbuin N, Budge M, Young J: Body mass index in midlife and late-life as a risk factor for dementia: a meta-analysis of prospective studies. Obes Rev 2011;12:e426-e437.

19 García-Ptacek S, Faxén-Irving G, Cermáková P, Eriksdotter M, Religa D: Body mass index in dementia. Eur J Clin Nutr 2014;68:1204-1209.

20 Qizilbash N, Gregson J, Johnson ME, Pearce N, Douglas I, Wing K, Evans SJ, Pocock SJ: BMI and risk of dementia in two million people over two decades: a retrospective cohort study. Lancet Diabetes Endocrinol 2015;3: 431-436.

21 Vidoni ED, Townley RA, Honea RA, Burns JM; Alzheimer's Disease Neuroimaging Initiative: Alzheimer disease biomarkers are associated with body mass index. Neurology 2011;77:1913-1920.

-22 Solfrizzi V, Panza F, Frisardi V, Seripa D, Logroscino G, Imbimbo BP, Pilotto A: Diet and Alzheimer's disease risk factors or prevention: the current evidence. Expert Rev Neurother 2011;5:677-708.

23 Lamport DJ, Saunders C, Butler LT, Spencer J: Fruits, vegetables, 100\% juices, and cognitive function. Nutr Rev 2014;12:774-789.

24 Dai Q, Borenstein AR, Wu Y, Jackson JC, Larson EB: Fruit and vegetable juices and Alzheimer's disease: the Kame Project. Am J Med 2006; 9:751-759.

-25 Hughes TF, Andel R, Small BJ, Borenstein AR, Mortimer JA, Wolk A, Johansson B, Fratiglioni L, Pedersen NL, Gatz M: Midlife fruit and vegetable consumption and risk of dementia in later life in Swedish twins. Am J Geriatr Psychiatry 2010;5:413-420.

26 Kuriyama S, Hozawa A, Ohmori K, Shimazu T, Matsui T, Ebihara S, Awata S, Nagatomi R, Arai H, Tsuji I: Green tea consumption and cognitive function: a cross-sectional study from the Tsurugaya Project. Am J Clin Nutr 2006;2:355-361.

27 Di Marco LY, Marzo A, Muñoz-Ruiz M, Ikram MA, Kivipelto M, Ruefenacht D, Venneri A, Soininen H, Wanke I, Ventikos YA, Frangi AF: Modifiable lifestyle factors in dementia: a systematic review of longitudinal observational cohort studies. J Alzheimers Dis 2014;42:119-135. 